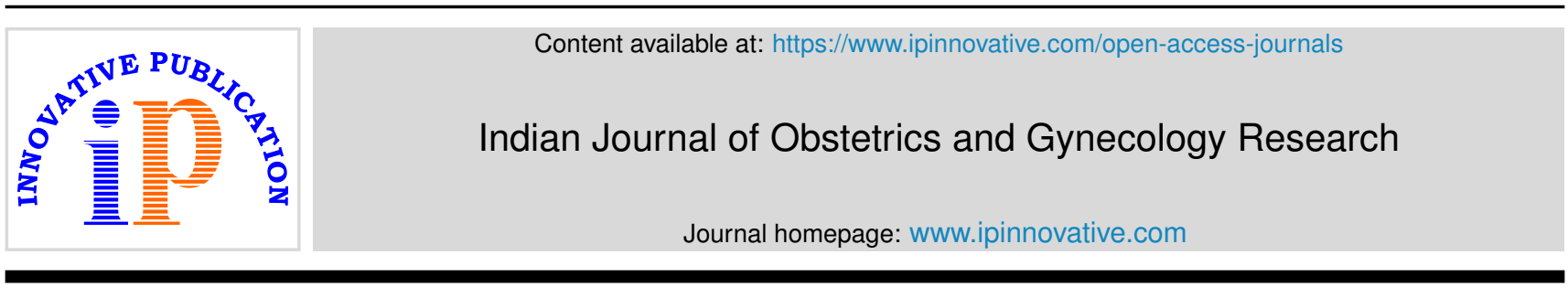

Original Research Article

\title{
Assessment of transvaginal ultrasound measurement of cervical length for prediction of spontaneous onset of labor at term
}

\author{
Shweta Walke ${ }^{1, *}$, Bhakti Deshpande ${ }^{2}$, Alka Patankar ${ }^{2}$ \\ ${ }^{1}$ Dept. of Obstetrics and Gynaecology, Government Medical College, Chandrapur, Maharashtra, India \\ ${ }^{2}$ Dept. of Obstetrics and Gynaecology, Indira Gandhi Government Medical College, Nagpur, Maharashtra, India
}

\section{A R T I C L E I N F O}

\section{Article history:}

Received 14-04-2020

Accepted 09-05-2020

Available online 12-09-2020

\section{Keywords:}

Transvaginal cervical length

Spontaneous onset of labor

\begin{abstract}
A B S T R A C T
Background: The objective of this study was to measure the cervical length by transvaginal sonography at term to predict onset and course of spontaneous labor.

Materials and Methods: One hundred and nighty nine pregnant women between 37 to 40 weeks of gestation who fulfilled the inclusion criteria were enrolled in this prospective observational study conducted in department of obstetrics and gynecology of IGGMC, NAGPUR.

Results: Out of 199 pregnant women, 154 women had full term vaginal delivery and 45 women underwent emergency cesarean section. The mean cervical length was $2.58 \mathrm{~cm}$ in women who had vaginal birth and was $3.45 \mathrm{~cm}$ in women who underwent emergency cesarean section. The best cutoff of transvaginal cervical length was $2.7 \mathrm{~cm}$ for predicting the spontaneous onset of labor within 7 days, having sensitivity of $90.91 \%$ and specificity of $84 \%$. The positive predictive value was $84.9 \%$ and negative predictive value of test $90.3 \%$, with diagnostic accuracy of $87.4 \%$.

Conclusions: When cervical length is less, then chances of vaginal delivery are significantly higher. Transvaginal cervical length measurement between 37 to 40 weeks is useful test for predicting spontaneous onset of labor within 7 days. It helps women and healthcare providers to plan vaginal birth and also timely decision of referral of those cases requiring immediate care to higher centres for better maternal and foetal outcome.
\end{abstract}

(C) 2020 Published by Innovative Publication. This is an open access article under the CC BY-NC license (https://creativecommons.org/licenses/by-nc/4.0/)

\section{Introduction}

One of the most common question a pregnant women asks is "when will I deliver?" and this question becomes even more frequent one to be asked as expected due date gets closer. Currently the best practice for estimating gestational age and due date uses combination of last menstrual period and early ultrasound, but this method is accurate only $5 \%$ of the times. With increasing availability of ultrasound, cervical length became easier to measure. The cervix consists mainly of connective tissue, containing about $85 \%$ collagen and elastin, while smooth muscles constitutes only $10-15 \%$. During pregnancy the firm cartilage like consistency of the cervix is transformed to soft tissue

\footnotetext{
* Corresponding author.

E-mail address: swkg999@gmail.com (S. Walke).
}

like. A decrease in collagen concentration and an increase elastin/collagen ratio softens the rigid structure of the cervix. This transformation is called 'Cervical Ripening' and enables the cervix to dilate and facilitate parturition. The human uterine cervix is a complex heterogenous organ that undergoes extensive changes throughout gestation and parturition. ${ }^{1}$ The objective of this study was to measure the cervical length by Transvaginal sonography at term to obtain more insight in physiological changes preceding parturition and to relate these changes to predict onset and course of spontaneous labour.

\section{Aims \& Objectives}

1. To calculate Sensitivity, Specificity, Positive Predictive Value and Negative Predictive Value 
of Transvaginal Sonographic Cervical Length Measurement between 37 to 40 weeks of gestation for Spontaneous onset of labour within 7 days.

2. To Study Maternal and Foetal Outcome in terms of mode of delivery, indication of LSCS in case of Cesarean birth, Birth weight and NICU admissions in Patients who were assessed by this method.

\section{Materials and Methods}

This was an observational study, conducted in department of Obstetrics and Gynecology at Indira Gandhi Government Medical College Nagpur. Informed consent was taken from all the subjects. All pregnant women fulfilling the inclusion criteria attending Antenatal Clinic at 37 weeks 40 weeks of pregnancy and willing to participate in study were enrolled. Data was collected in a preconceived format. Information regarding details of demographic characteristics, presenting clinical symptoms and signs, parity, use of contraception, detailed obstetric history, including other morbidity (if any) was obtained. Relevant investigations were done for the same. All the patients were subjected to transvaginal ultrasound for Cervical length measurement in the department of Obstetrics \& Gynaecology. All aseptic precautions were followed. We studied 199 Antenatal women who attended clinics at 37 weeks 40 weeks of pregnancy. Institutional ethics committee approval was obtained.

\subsection{Inclusion criteria}

1. Primigravida and Multigravida patients between 37 week to 40 weeks of gestation, not in labor.

2. Single live foetus in Cephalic presentation.

3. With Intact Membranes.

4. Without any previous uterine scar.

\subsection{Exclusion criteria}

1. Women attending antenatal clinic before 37 weeks or after 40 weeks.

2. With premature rupture of membrane.

3. With multiple gestation, previous LSCS, abnormal presentation.

4. Planned cesarean section.

5. Bad obstetrics history.

6. History of cervical encirclage.

7. High risk pregnancies with medical or obstetric comorbidities.

\section{Results}

One hundred and ninety nine patients with gestational age between 37-40 weeks were enrolled in our study. Most of the cases were in the age group of 25years to 30 years and mean age was 25.1 years. Majority of women i.e.84(42.21\%) had cervical length between 2.6$3 \mathrm{~cm}$. Table 1 depicts the distribution of patients undergoing spontaneous onset of labor before 7 days of measurement of cervical length by TVS, which was the primary outcome variable. 99 women had onset of labor on or after 7 days of measurement.

Table 1: Distribution of cases according to time interval from Gestational age at cervical length measured to gestational age at onset of labour

\begin{tabular}{lcc}
\hline Time interval & Number of Cases & Percent \\
$<7$ days & 100 & 50.25 \\
$\geq 7$ days & 99 & 49.75 \\
Total & 199 & 100 \\
\hline
\end{tabular}

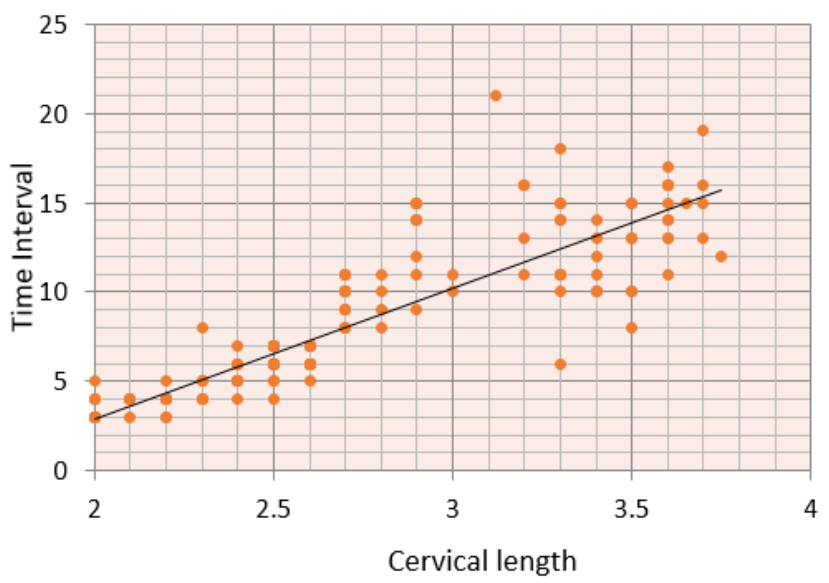

Fig. 1: Correlation of cervical length and Time interval for spontaneous labour onset

As in Figure 1 shows positive correlation between time interval from measurement of cervical length to spontaneous onset of labor. The best cutoff of cervical length given is $2.7 \mathrm{~cm}$.

Table 2 demonstrates that if mean cervical length is less then chances of vaginal delivery are higher and the mean cervical length in patients who had LSCS was significantly higher with a mean of $3.45 \mathrm{~cm}$ ( $\mathrm{p}$ value of $<0.0001$ ).

Table 2: Comparison of cervical length according to mode of delivery

\begin{tabular}{lcc}
\hline Mode of delivery & $\begin{array}{c}\text { Mean Cervical } \\
\text { length in cm }\end{array}$ & p-value \\
FTND & $2.58 \pm 0.30$ & $\mathrm{t}=18.3019$ \\
LSCS & $3.45 \pm 0.15$ & $\mathrm{P}<0.0001, \mathrm{HS}$ \\
\hline
\end{tabular}

Table 3 demonstrates that women who had a spontaneous onset of labour within 7 days of measurement had a significantly lower mean cervical length of $2.47 \mathrm{~cm}$., when compared to women delivered after 7 days or more with a mean cervical length of $3.08 \mathrm{~cm}$. (p value $<0.0001 \mathrm{HS}$ ). 
Table 3: Comparison of mean cervical length and time interval from cervical length measurement to Gestational age at onset of labor

\begin{tabular}{lcc}
$\begin{array}{l}\text { Time interval from } \\
\text { cervical length measured } \\
\text { at GA to Gestational age } \\
\text { at onset of labor }\end{array}$ & $\begin{array}{c}\text { Mean } \pm \text { SD } \\
\text { Cervical } \\
\text { Length }\end{array}$ & p-value \\
$<7$ days & $2.47 \pm 0.31$ & \\
$\geq 7$ days & $3.08 \pm 0.36$ & $\mathrm{t}=12.7091$ \\
\hline
\end{tabular}

As seen in Table 4 and Figure 2, the best cutoff of transvaginal cervical length is $2.7 \mathrm{~cm}$ for predicting the spontaneous onset of labor within 7 days, having sensitivity of $90.91 \%$ and specificity of $84 \%$, the positive predictive value is $84.9 \%$ and negative predictive value of test $90.3 \%$, with diagnostic accuracy of $87.4 \%$ of the test.

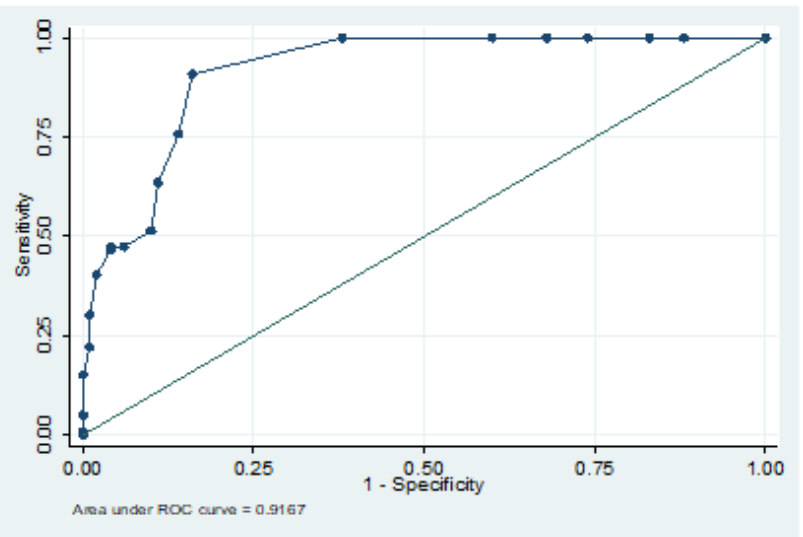

Fig. 2: Receiving operating characteristic curve for prediction of spontaneous delivery within 7 days on the basis of cervical length

\subsection{Statistical analysis}

Continuous variables were presented as Mean \pm SD. Categorical variables were expressed in frequency and percentages. Mean Cervical length was compared between FTND \& LSCS and also between time interval by performing independent t-test. Categorical variables were compared by performing chi2-square test. For small numbers, Fisher exact test was used wherever applicable. Correlation coefficient ( $r$ ) was used to assess the correlation between cervical length and time interval. Receiving Operating Characteristic Curve analysis was carried out for prediction of spontaneous onset of labour within 7 days on the basis of cervical length. Sensitivity, specificity, PPV, NPV and diagnostic accuracy was calculated for diagnostic evaluation. $\mathrm{p}<0.05$ was considered as statistical significance. Statistical software STATA version 14.0 was used for statistical analysis.

\section{Discussion}

Our study was conducted on 199 low risk antenatal women registered in the department of Obstetrics and Gynecology at Tertiary Care centre. In our study we found that most of the cases were in age group between 25 years to 30years of age and mean age was 25 years. There was no correlation between age of patient and cervical length at term. Majority of our patients were multiparous. Although study of effect of parity on the predictive value of cervical length for spontaneous onset of labour was outside the purview of our study, we found similar study by Vankayalapati ${ }^{2}$ conducted previously which shows direct effect of parity on cervical length at term. In their study, the data was analyzed according to parity, where they found that, the ability of cervical length measurement to predict spontaneous onset of labor disappears for parous women.

In our study we found that when the cervical length is less, the chances of vaginal delivery are significantly higher. Mean cervical length was $2.58 \mathrm{~cm}$, in women who delivered vaginally, while the mean cervical length was higher at 3.45 $\mathrm{cm}$ in women who underwent emergency cesarean section and this difference was statistically significant. In our study we also found that when mean cervical length was less than $2.5 \mathrm{~cm}$ then Mean time interval for spontaneous onset of labor was in 4 days but when mean cervical length was more than $2.5 \mathrm{~cm}$ then the mean time interval of spontaneous onset of labor was 9 days.

Bayramoglu et al. ${ }^{3}$ in 2005 reported on a cohort of 93 women at 37-40 weeks and assessed the relationship between CL and delivery within 7 days. Using the ROC curve, they identified optimal cutoff measurements (29.5, $27.5,25.5$ and $24.5 \mathrm{~mm}$ ) at $37,38,39$ and 40 weeks respectively. Their findings also demonstrate the utility of CL in predicting either outcome, independent of specific gestational age at ultrasound.

In our study we found that the mean cervical length was $2.47 \mathrm{~cm}$, in women who had spontaneous onset of labor within 7 days, while mean cervical length was $3.08 \mathrm{~cm}$, in women who had spontaneous onset of labor on or after 7 days. Some previously published studies assessed CL at term (37 weeks' gestation), attempting to evaluate the relationship between sonographic measurement of CL and time to delivery. ${ }^{3}$

Previously Vankayalapati ${ }^{2}$ et al mentioned that shorter the cervix, sooner the chances of spontaneous onset of labor. The area under the ROC curve for onset of labor within 4 days in this study ( 0.683 nulliparous, 0.588 parous) was very similar to that reported by Strobel et al. (0.706 nulliparous, 0.583 parous). Strobel et al. studied 97 women at 42 weeks and found that cervical length is an independent predictor of the spontaneous onset of labor. ${ }^{4}$

Tolaymat $^{5}$ et al study found that in singleton pregnancies, CL at 37-40 weeks is an independent predictor of the outcomes spontaneous labor within 7 
Table 4: Diagnostic evaluation of cervical length for prediction of spontaneous deliveries within 7 days

\begin{tabular}{|c|c|c|c|c|c|c|c|}
\hline $\begin{array}{l}\text { Area under } \\
\text { curve }\end{array}$ & $95 \%$ C.I. & $\begin{array}{l}\text { Best cut off } \\
\text { in } \mathbf{~ c m ~}\end{array}$ & Sensitivity & Specificity & PPV & NPV & $\begin{array}{c}\text { Diagnostic } \\
\text { accuracy }\end{array}$ \\
\hline 0.9167 & $0.87-0.95$ & $\geq 2.7$ & $90.91 \%$ & $84.0 \%$ & $84.9 \%$ & $90.3 \%$ & $87.4 \%$ \\
\hline
\end{tabular}

days and delivery by 41 weeks regardless of the specific gestational age at the time of ultrasound or parity. The overall prevalence of spontaneous labor within 7 days in their cohort was low (32.8\%), likely reflecting the exclusion of women who complained of contractions at the time of enrollment. The advantage of Transvaginal sonography compared to digital examination of the cervix were recognized shortly after its introduction. Early cervical ripening resulting in changes at the internal cervical os, can be observed by transvaginal sonography even in the absence of dilatation. Nowadays it is considered to be reproducible. ${ }^{5,6}$

Meijer Hoogeveen $\mathrm{M}^{7}$ et al. study demonstrated a large inter-individual variation in CL and in CL changes before the spontaneous onset of labour at term. The last CL measurement was only weakly correlated with the time until spontaneous onset of labour, and even in the last 48 hours prior to delivery, a quarter of their population still had a CL greater than $30 \mathrm{~mm}$. CL was not correlated with gestational age. In only half of the population they found a decrease in CL preceding labour, either gradual over the weeks or within the last two weeks before delivery. In the others CL remained unchanged until shortly before delivery. This large variation interferes with the prediction of spontaneous onset of labour by a single CL measurement at any point in time at term. Their data indicate that in about half of the nulliparous population no CL changes occur in the 3 to 5 weeks prior to delivery, at least not until 48 hours before spontaneous onset of labour. ${ }^{8}$ Previous studies have reported normal ranges for CL during pregnancy. ${ }^{9-11}$ Bergelin et al performed CL measurements every two weeks from midgestation to delivery at term in 19 nulliparous women, ${ }^{12}$ and 21 parous women. ${ }^{13}$ In most women they found a gradual or accelerated decrease in CL prior to delivery. Two earlier studies investigated the sonographic $\mathrm{CL}$ at 37 weeks of gestation as a predictor of spontaneous onset of labour before 41 weeks of gestation. ${ }^{3,14}$ They found a high PPV (95\% and 92\%, respectively) with a CL of $30 \mathrm{~mm}$ as an optimal cut-off point. These findings were similar for CL measurements taken in supine and upright position. They concluded that, inter-individual variation in $\mathrm{CL}$ and in $\mathrm{CL}$ changes are large at term. This large variation interferes with the prediction of spontaneous onset of labour by a single CL measurement at any point in time.

We observed that best cut-off $\mathrm{CL}$ of $<27 \mathrm{~mm}$ using ROC between 37 and 40 weeks of gestation appears to predict spontaneous onset of labour before 41 weeks of gestation, but with $90.91 \%$ sensitivity and $90.3 \%$ NPV and $84.9 \%$ PPV, with diagnostic accuracy of $87.4 \%$. Our results were better than the results of another study by Rozenberg et al. ${ }^{15}$ who in 2000 enrolled 128 women with singleton pregnancies at 39-40 weeks and found an association between CL and the likelihood of spontaneous onset of labor within 7 days. They chose a CL of $26 \mathrm{~mm}$ based on an ROC curve, but the reported sensitivity, specificity, PPV and NPV were $56.5,71.1,76.1$ and $50 \%$ respectively. They found a cutoff of $25 \mathrm{~mm}$ has the best sensitivity and NPV of 77.5 and $84.7 \%$ respectively.

In Joydev Mukherji et al ${ }^{16}$ study majority of patient did not show change $>5 \mathrm{~mm}$ per week. They found the notable decrease in CL preceding labor in only third of sample which was over the last three weeks before delivery. In others, CL remain largely unchanged until shortly before delivery. It was ascertained the CL $>31 \mathrm{~mm}$ by TVS at 38 weeks of gestation could predict postdated pregnancy to some degree but this study had limitation that it was not continued beyond 40 completed week of gestation, hence it was not clear what happened to the cervical changes in postdated pregnancy. Souka. ${ }^{17}$ et.al found that a significant proportion of pregnancy destined to deliver at term had short cervical measurement.

In Sacconeg et $\mathrm{al}^{18}$ study found that for prediction of spontaneous labor within 7 days for cervical length $<30 \mathrm{~mm}$ the pooled Sensitivity was $64 \%$ and pooled Specificity was $60 \%$.The higher the $\mathrm{CL}$, the better the sensitivity, the lower the CL, the better the specificity. A woman with a singleton gestation at term with a TVU CL of $30 \mathrm{~mm}$ has less than $50 \%$ chance of delivering within 7 days while one with TVU of $10 \mathrm{~mm}$ has an over $85 \%$ chance of delivery within in 7 days. TVU CL at term has moderate value in prediction of spontaneous of labor.

In a study by Mahutkuntay Kokanali et al ${ }^{19}$ study CL was measure by TVU at 34 weeks GA in 318 women (singleton, nulliparous, low risk, vertex presentation). All women were followed till birth and delivered at hospital. Deliveries were classified according to gestational week as late preterm $34(0 / 7)$ to $36(6 / 7)$, term $37(6 / 7)$ to $40(0 / 7)$, late term $41(0 / 70$ to $41(6 / 7)$. There was significant correlation between $\mathrm{CL}$ at 34 weeks and gestational age at delivery $(\mathrm{r}=0.614, \mathrm{p}<0.001)$. The ROC analysis showed that $\mathrm{CL}$ measurement $<25.5 \mathrm{~mm}$ predicted late preterm delivery with a sensitivity of $80.0 \%$, specificity of $93.9 \%$, PPV of $52.61 \%$ and NPV of $98.2 \%$, while CL above $42.5 \mathrm{~mm}$ had $70.4 \%$ sensitivity, $93.5 \%$ specificity, $50.0 \%$ of PPV and $97.1 \% \mathrm{NPV}$ in prediction of late-term deliveries.

In settings where transvaginal measurement of cervical length is possible, it's a useful test to predict spontaneous onset of labor and for timely referral of complicated 
cases to higher centres for better maternal and neonatal outcome, women with cervical length less than $2.7 \mathrm{~cm}$ can be counselled for the spontaneous onset of labor within 7 days and that with cervical length more $3 \mathrm{~cm}$, they have higher chances of delivering after more than 7 days.

\section{Conclusion}

Transvaginal cervical length measurement between 37 to 40 weeks of gestation is a useful test for predicting spontaneous onset of labor within 7 days. It helps the woman and healthcare providers to plan the vaginal birth and also timely decision can be taken for the referral of those cases requiring immediate care to higher centers for better maternal and foetal outcome.

\section{Source of Funding}

None.

\section{Conflict of Interest}

None.

\section{References}

1. Yu SY, Leppert PC. The collagenous tissues of the cervix during labor and delivery. In: Leppert PC, Woessner JF, editors. The extracellular matrix of the cervix, uterus and fetal membranes: Synthesis, Degradation and Hormonal Regulation. Ithaca, NY: Perinatology Press; 1991. p. 68-76.

2. Vankayalapati P, Sethna F, Roberts N, Ngeh N, Thilaganathan B, Bhide A. Ultrasound assessment of cervical length in prolonged pregnancy: prediction of spontaneous onset of labor and successful vaginal delivery. Ultrasound Obstet Gynecol. 2008;31(3):328-31.

3. Bayramoglu Ö, Arslan M, Yazici FG, Erdem A, Erdem M, Bayramoglu K, et al. Prediction of Spontaneous Onset of Labor at Term: The Role of Cervical Length Measurement and Funneling of Internal Cervical Os Detected by Transvaginal Ultrasonography. Am J Perinatol. 2005;22(01):35-9.

4. Strobel E, Sladkevicius P, Rovas L, Smet FD, Karlsson ED, Valentin L. Bishop score and ultrasound assessment of the cervix for prediction of time to onset of labor and time to delivery in prolonged pregnancy. Ultrasound Obstet Gynecol. 2006;28(3):298-305.

5. Tolaymat LL, Gonzalez-Quintero VH, Sanchez-Ramos L, Kaunitz A, Wludyka P, O'Sullivan MJ, et al. Cervical length and the risk of spontaneous labor at term. J Perinatol. 2007;27(12):749-53.

6. Valentin L, Bergelin I. Intra- and interobserver reproducibility of ultrasound measurements of cervical length and width in the second and third trimesters of pregnancy. Ultrasound Obstet Gynecol. 2002;20(3):256-62.

7. Hoogeveen MM, Stoutenbeek P, Visser GHA. Methods of sonographic cervical length measurement in pregnancy: A review of the literature. J Matern Fetal Neonatal Med. 2006;19(12):755-62.
8. Leppert PC, Cerreta JM, Mandl I. Orientation of elastic fibers in the human cervix. Am J Obstet Gynecol. 1986;155(1):219-24.

9. Gramellini D, Fieni S, Molina E, Berretta R, Vadora E. Transvaginal Sonographic Cervical Length Changes During Normal Pregnancy. $J$ Ultrasound Med. 2002;21(3):227-32.

10. Tongsong T, Kamprapanth P, Pitaksakorn J. Cervical length in normal pregnancy as measured by transvaginal sonography. Int $J$ Gynecol Obstet. 1997;58(3):313-5.

11. Zorzoli A, Soliani A, Perra M, Caravelli E, Galimberti A, Nicolini U. Cervical Changes Throughout Pregnancy As Assessed by Transvaginal Sonography. Obstetrics and Gynecology. 1994;84(6):960-964.

12. Bergelin I, Valentin L. Patterns of normal change in cervical length and width during pregnancy in nulliparous women: a prospective, longitudinal ultrasound study. Ultrasound Obstet Gynecol. 2001;18(3):217-22.

13. Bergelin I, Valentin L. Normal cervical changes in parous women during the second half of pregnancy - a prospective, longitudinal ultrasound study. Acta Obstet Gynecol Scand. 2002;81(1):31-8.

14. Ramanathan G, Yu C, Osei E, Nicolaides KH. Ultrasound examination at 37 weeks' gestation in the prediction of pregnancy outcome: the value of cervical assessment. Ultrasound Obstet Gynecol. 2003;22(6):598-603.

15. Rozenberg P, Goffinet F, Sage-Femme MH. Comparison of the Bishop score, ultrasonographically measured cervical length, and fetal fibronectin assay in predicting time until delivery and type of delivery at term. Am J Obstet Gynecol. 2000;182(1):108-13.

16. Mukherji J, Bhadra A, Ghosh SK, Hazra A, Anant M, Bhattacharya $\mathrm{SK}$, et al. Cervical length measurement in nulliparous women at term by ultrasound $\&$ its relationship to spontaneous onset of labour. Indian J Med Res. 2017;146:498.

17. Souka AP, Papastefanou I, Papadopoulos G, Chrelias C, Kassanos D. Cervical length in late second and third trimesters: a mixture model for predicting delivery. Ultrasound Obstet Gynecol. 2015;45(3):308-12.

18. Saccone G, Simonetti B, Berghella V. Transvaginal ultrasound cervical length for prediction of spontaneous labour at term: a systematic review and meta-analysis. Int $J$ Obstet Gynaecol. 2016;123(1):16-22.

19. Kokanali MK, Çelik H, Kokanali D, Taşçi Y. Predictive role of transvaginal ultrasonographic measurement of cervical length at 34 weeks for late pre-term and late-term deliveries in nulliparous women. J Maternal-Fetal Neonatal Med. 2016;29(11):1789-94.

\section{Author biography}

Shweta Walke Senior Resident

Bhakti Deshpande Senior Assistant Professor

Alka Patankar Associate Professor

Cite this article: Walke S, Deshpande B, Patankar A. Assessment of transvaginal ultrasound measurement of cervical length for prediction of spontaneous onset of labor at term. Indian J Obstet Gynecol Res 2020;7(3):421-425. 